\title{
Recovery of Pyrenophora tritici-repentis from Barley and Reaction of 12 Cultivars to Five Races and Two Host-Specific Toxins
}

\author{
S. Ali and L. J. Francl, Department of Plant Pathology, North Dakota State University, Fargo, ND 58105
}

\begin{abstract}
Ali, S., and Francl, L. J. 2001. Recovery of Pyrenophora tritici-repentis from barley and reaction of 12 cultivars to five races and two host-specific toxins. Plant Dis. 85:580-584.

Barley, a collateral host of Pyrenophora tritici-repentis (cause of tan spot of wheat), could promote genetic variation in the fungal population and serve as a reservoir of local primary inoculum for a wheat crop in the next season. Samples of diseased barley leaves were collected from 35 locations in North Dakota during the 1999 growing season. P. tritici-repentis was recovered from 2 to $5 \%$ of the sampled lesions taken from three of the samples. The majority of the samples also harbored Pyrenophora teres, Stagnospora nodorum, and Cochliobolus sativus. All 10 isolates of $P$. tritici-repentis recovered from the samples were grouped as race 1, because they induced both necrosis and chlorosis on the appropriate wheat differentials. In addition, 12 barley cultivars were tested for their reaction to five races of $P$. tritici-repentis, and all were resistant. The fungus could not be recovered when isolations were later attempted from the inoculated leaves. Barley cultivars also were infiltrated with two host-specific toxins, Ptr ToxA and ToxB. They were insensitive, because they did not develop necrosis or chlorosis to the toxins. Our results indicate that barley is highly resistant to the fungus and is unaffected by its hostspecific toxins. Prevalence of race 1 in a very low frequency on barley during the growing season suggests that barley does not play a significant role in tan spot epidemiology on wheat or promote variation in the fungal population.
\end{abstract}

Additional keywords: alternate host, phytotoxins

Pyrenophora tritici-repentis (Died.) Drechs. (anamorph = Drechslera triticirepentis (Died.) Shoemaker) is the cause of tan spot and pink smudge of wheat (Triticum aestivum L.). Symptoms on susceptible lines are oval-shaped necrotic leaf spots surrounded by chlorosis. Yield losses have ranged from $3 \%$ to $53 \%$, depending on the cultivar susceptibility, environmental conditions, and virulence of the pathogen population $(14,30)$. The fungus can survive from one cropping season to the next on infested crop residue, infected seed, and collateral host plants $(14,21,32)$; however, the mode of overwintering varies in importance from place to place. In the northern Great Plains of the United States, wheat crop residue is the major source of primary inoculum, especially where conservation tillage is practiced.

Genetic variation in $P$. tritici-repentis populations has been observed repeatedly $(1,2,3,14,23,28)$. Fungal isolates can be separated into five races based on their

Corresponding author: Leonard J. Francl

E-mail: Leonard_Francl@ndsu.nodak.edu

Accepted for publication 16 February 2001

Publication no. D-2001-0412-01R

(C) 2001 The American Phytopathological Society ability to induce necrotic and/or chlorotic symptoms on appropriate wheat differentials $(22,24)$. In the northern Great Plains, races $1,2,4$, and 5 have been identified $(1,2,3)$. Three host-specific toxins, Ptr ToxA, ToxB, and ToxC, have been isolated and associated with the development of necrosis and chlorosis $(5,7,10,35)$. The mechanisms of these host-specific toxins in disease development at the molecular level are under investigation $(6,17)$.

P. tritici-repentis has been reported as pathogenic on several grass species $(9,15,21)$ and was said to have a relatively wide host range compared to other Drechslera species (33). Fungal isolates recovered from collateral hosts were crosspathogenic on wheat and vice versa $(15,18)$. Moreover, the fungal isolates from different host plants were found to vary in their virulence and aggressiveness $(1,2,18)$. Barley (Hordeum vulgare L.) was found to be intermediate in susceptibility to the fungus when grass species were inoculated with fungal isolates obtained from wheat and alternate host species (18). The fungus was reisolated from $43 \%$ of inoculated leaf pieces (18). Barley was highly resistant to the fungus in other studies conducted in the United States and Belgium $(13,15,25)$. The fungus was isolated only from naturally infected leaves and only from yellow spots before leaf senescence $(13,34)$, but was isolated from all sites after leaf senescence on the highly resistant barley cultivar O'Conner (34). In addition, P. triticirepentis was not observed on barley samples in a field study on the survival of leafspotting fungal pathogens in crop residues of wheat and barley (9).

In North Dakota, barley often is planted beside wheat or where wheat was planted the previous year. As barley is considered a collateral host of $P$. tritici-repentis, assessment of barley host specificity is of great importance for understanding its role in the establishment of the pathogen in wheat and as a source of variation in the pathogen population. In previous host range studies, one or two barley lines were tested for their reaction to pathogen isolates $(15,25)$. These studies were conducted before the race system was developed, and host-specific toxins were not known. Therefore, the reaction of barley cultivars to all known races of $P$. triticirepentis and toxins still needs investigation. In this study we addressed: (i) recovery and race characterization of $P$. triticirepentis from diseased leaves of barley collected from various locations in North Dakota; (ii) reaction of 12 barley cultivars to $P$. tritici-repentis races 1 to 5 , and (iii) sensitivity of the 12 cultivars to Ptr ToxA and Ptr ToxB.

\section{MATERIALS AND METHODS}

Recovery and characterization of $P$. tritici-repentis isolates from barley. Thirty-five samples of barley leaves with necrotic spots were collected from six North Dakota counties (Cass, Griggs, Nelson, Ramsey, Steele, and Traill). The samples were collected on 30 July 1999 from arbitrary fields beside Interstate 29, ND 200, ND 32, ND 15, and ND 1. The leaves were air-dried by placing them on a laboratory bench in front of a fan, then storing them dry on a laboratory bench. To recover the fungus, leaves of each collected sample were cut into $1.0-$ to $1.5-\mathrm{cm}$ pieces so that a lesion was cut through the center. With this technique, conidia are produced on the edge of the leaf piece, making it easy to transfer an individual conidium. Forty- to 45-leaf pieces were randomly selected from each sample and placed in petri dishes covered with three layers of Whatman no. 1 dampened filter paper. The dishes were incubated under fluorescent 
light for $24 \mathrm{~h}$ at $22^{\circ} \mathrm{C}$, then incubated in the dark for $24 \mathrm{~h}$ at $16^{\circ} \mathrm{C}$ to induce conidiophores and conidia of $P$. tritici-repentis. Conidia of Drechslera species from incubated leaf pieces were collected under a stereomicroscope with a sterilized fine-tip steel needle placed in V8 potato dextrose agar (PDA) medium (23). This procedure makes the needle sterile and sticky, making it easy to pick a single conidium from the leaf piece. Five conidia were transferred onto one petri dish of V8 PDA medium and placed 4 to $5 \mathrm{~cm}$ apart. To make sure that a single conidium was transferred, the dish was examined under the stereomicroscope. The petri dishes were incubated at $22^{\circ} \mathrm{C}$ for 3 days and conidial germination was examined. Each colony from a singlespore isolate was transferred individually onto a fresh V8 PDA petri dish. These dishes were incubated at $22^{\circ} \mathrm{C}$ in darkness for 5 days or until the colony growth reached about $7 \mathrm{~cm}$ in diameter. Then the isolates were prepared for storage by following the procedure of Jordahl and Francl (16).

Single-spore isolates of Drechslera species were identified from subcultures based on their morphology (33). Drechslera teres (Sacc) Shoem., a barley pathogen, produces dark green conidia with round basal cells, and in most cases more than two conidia are produced on a single conidiophore. Whereas D. tritici-repentis conidia are light olive green, longer in size and each conidiophore usually produces a single conidium.

Inoculum production and inoculations. Inoculum was produced from isolates stored at $-20^{\circ} \mathrm{C}$ throughout the experiment. The plugs of each isolate were transferred to four petri dishes of V8 PDA and were incubated for 4 days or until the colony diameter reached $4 \mathrm{~cm}$. Thereafter, the petri dishes were flooded with sterilized distilled water, and hyphal growth was knocked down with a flame-sterilized glass test tube. After suppressing the hyphae, excess water was decanted from the dishes. Plates were incubated in an alternate cycle of $24 \mathrm{~h}$ light at $22^{\circ} \mathrm{C}$ and $24 \mathrm{~h}$ dark at $16^{\circ} \mathrm{C}$ to induce conidiophores and conidia. Thirty $\mathrm{ml}$ of distilled sterilized water were added to each dish. The conidia were dislodged with an inoculating needle with a looped wire, and the conidial suspension was decanted. The dishes were rinsed by an additional $30 \mathrm{ml}$ of distilled sterilized water. The conidial suspension was adjusted to 3,500 spores per $\mathrm{ml}$ following the procedure described by Jordahl and Francl (16). Tween 20 was added at one drop/100 $\mathrm{ml}$ of the spore suspension before inoculation.

All P. tritici-repentis isolates were typed to race by inoculating them individually on the wheat differential set developed by Lamari and Bernier (22) (Table 1). Two wheat genotypes, ND 495 and M-3, were included with the differentials to enhance the chances of detecting variants of races in the pathogen population. The isolates were assayed in the greenhouse on seedlings at the two-leaf stage. Three seedlings of each differential line were produced in plastic cones $(3.8 \mathrm{~cm}$ in diameter and 20 $\mathrm{cm}$ in length) filled with Fison sunshine blend no. 1 (Fison Horticulture, Vancouver, $\mathrm{BC}$ ) and grown in the greenhouse at an average temperature of $21^{\circ} \mathrm{C}$ with a $16-\mathrm{h}$ photoperiod. The seedling leaves were kept dry while plants were watered to decrease the chance of saprophytic growth of microorganisms, which could interfere with the results. Three cones of each differential line were arranged in a rack in a completely randomized design. The seedlings were inoculated at 3,500 spores per $\mathrm{ml}$ of each isolate individually until run off. Inoculated seedlings were moved to a mist chamber at $21^{\circ} \mathrm{C}$ with a 16 -h photoperiod for $24 \mathrm{~h}$. The chamber was misted for 16 $\mathrm{sec}$ at 3-min intervals. Thereafter, the plants were moved to a growth chamber at $22^{\circ} \mathrm{C}$. The plants were rated for symptom development 8 days postinoculation, using the 1 to 5 rating scale $(1=$ very resistant and $5=$ very susceptible) developed by Lamari and Bernier (22).

Reaction of barley genotypes to $P$. tritici-repentis races and host-specific toxins. Seedlings of 12 barley lines were screened in the greenhouse for their reaction to $14 P$. tritici-repentis isolates representative of races 1 to 5 (Tables 2 and 3 ). The lines were selected with different inflorescence types (two-row or six-row), growth habits (spring or winter), and pedigrees (bred in the United States or India between 1944 or earlier and 1993). Seedling age varied from 17 to 19 days because of variability in germination. Seedlings of two susceptible wheat lines, ND495 and Katepwa, and one resistant wheat line, M3 , were included as checks for validation of the inoculation. An isolate 89-19 of $P$. teres, obtained from barley, also was included in the experiment as a check. Leaves of all 12 barley lines inoculated with the fungal isolates Pti2, 86-124, 3319, 88-1, and DW7 were sampled for fungal isolation 12 days post-inoculation to complete Koch's postulates. Isolations were

Table 1. Reaction of wheat lines to Pyrenophora tritici-repentis races

\begin{tabular}{|c|c|c|c|c|c|c|}
\hline \multirow[b]{2}{*}{ Races } & \multicolumn{6}{|c|}{ Wheat lines } \\
\hline & Glenlea $^{a}$ & $\mathrm{ND495}^{\mathrm{b}}$ & Katepwa $^{a}$ & $6 B 365^{a}$ & Salamouni $^{a}$ & $\mathbf{M}-\mathbf{3}^{\mathbf{b}}$ \\
\hline 1 & Necrosis & Necrosis & Necrosis & Chlorosis & Resistant & Resistant \\
\hline 2 & Necrosis & Necrosis & Necrosis & Resistant & Resistant & Resistant \\
\hline 3 & Resistant & Resistant & Resistant & Chlorosis & Resistant & Resistant \\
\hline 4 & Resistant & Resistant & Resistant & Resistant & Resistant & Resistant \\
\hline 5 & Resistant & Resistant & Chlorosis & Resistant & Resistant & Resistant \\
\hline
\end{tabular}

a Differential lines established by Lamari and Bernier (23).

$\mathrm{b}$ Lines added in this study.

Table 2. Barley cultivars tested for their reaction to five Pyrenophora tritici-repentis races and two host-specific toxins

\begin{tabular}{lllll}
\hline Cultivar $^{\mathbf{a}}$ & Type & Habit & Pedigree & Source/released \\
\hline Azure & Six-row & Spring & Bonanza//Nordic/NDB130 & North Dakota 1982 \\
Bowman & Two-row & Spring & Klages//Fergus/Nordic/3/ND1156/4/Hector & North Dakota 1984 \\
Breeder & Six row & Spring & Unknown & Minnesota 1990 \\
Excel & Six-row & Spring & Cree/Bonanza//Manker/3/2*Robust & \\
Firlbeck & Six row & Spring & Unknown & India \\
Manduria & Six row & Spring & Unknown & South Dakota 1966 \\
Monte Cristo & Six-row & Winter & Unknown & North Dakota1944 \\
Primus & Six-row & Spring & Brandon 3902/Liberty//Swan & Minnesota, 1993 \\
Kindred & Six-row & Spring & Rust resistant single plant selection from Wisconsin pedigree 37 & Alberta, Canada 1954 \\
Stander & Six-row & Spring & Excel//Robust/Bumper & Minnesota 1983 \\
Wolfe & Six-row & Spring & Sanalta/Titan//Montcalm/olli & \\
Robust & Six-row & Spring & Morex/Manker &
\end{tabular}

a Seed was provided by Dr. Thomas Fetch, Department of Plant Pathology, North Dakota State University. 
made as described earlier except the number of leaf pieces were 20 to 25 instead of 40 to 45 . The experiment was repeated once with an interval of one week between experiments.

The same seedlings of barley lines tested five days before inoculation with the spore suspension for their reaction to $14 P$. tritici-repentis isolates were tested for their reaction to purified Ptr ToxA at $10 \mu \mathrm{g} / \mathrm{ml}$ and ToxB culture filtrate diluted 10 -fold in distilled sterilized water. Four leaves of each line were infiltrated as described by Faris et al. (11) with pure Ptr ToxA and Ptr ToxB culture filtrate separately. The second leaves were infiltrated and rated for their reaction five days postinfiltration. The experiment was conducted twice. Both fungal and toxin experiments used the same plants, which avoided experimental variation due to possible seed mixture or genotype variability.

\section{RESULTS AND DISCUSSION}

Recovery of Pyrenophora tritici-repentis and its race structure from barley samples. P. tritici-repentis was isolated from 3 of 35 samples at a frequency ranging from 2 to $5 \%$. The majority of the samples were infected with $P$. teres, Stagnospora nodorum (Berk.) E. Castell. \& Germano, and Cochliobolus sativus (Ito \& Kurib.) Drechs. ex Dastur. (Table 4). Cochliobolus sativus and $P$. teres are primary pathogens of barley and invade leaves more aggressively than $P$. tritici-repentis. $P$. triticirepentis had been successfully isolated from field-collected barley leaf samples

Table 3. Pyrenophora tritici-repentis isolates tested for their reaction on 12 barley cultivars

\begin{tabular}{llll}
\hline Isolate & Race & Source & Location \\
\hline Pti2 & 1 (nec+chl+) & Wheat & South Dakota \\
$107-1$ & $1($ nec+chl+) & Barley & North Dakota \\
ASC1 & 1 (nec+chl+) & Wheat & Canada \\
OK12 & 1 (nec+chl+) & Wheat & Oklahoma \\
$86-124$ & $2($ nec+chl-) & Wheat & Canada \\
ARD1 & $2($ nec+chl-) & Wheat & Argentina \\
UR3 & $2($ nec+chl-) & Wheat & Uruguay \\
$331-9$ & $3($ nec-chl+) & Wheat & Canada \\
$88-1$ & $4($ nec-chl-) & Wheat & Canada \\
MD122 & $4($ nec-chl-) & Smooth bromegrass & North Dakota \\
WB1 & $4($ nec-chl-) & Wild barley & North Dakota \\
DW5 & $5($ nec-chl+) & Durum & North Dakota (1998) \\
DW7 & $5($ nec-chl+) & Durum & North Dakota (1998) \\
DW10 & 5 (nec-chl+) & Durum & North Dakota (1998) \\
\hline
\end{tabular}

Table 4. Fungi associated with 35 barley leaf samples collected from various locations in North Dakota

\begin{tabular}{lcc}
\hline Species & Number of samples with the fungus & Infection incidence $^{\mathbf{a}} \boldsymbol{( \% )}$ \\
\hline Cochliobolus sativus & 35 & $13.2-84.0$ \\
Drechslera teres & 34 & $3.6-73.5$ \\
Drechslera tritici-repentis & 3 & $2.2-5.1$ \\
Stagonospora nodorum & 31 & $5.6-56.5$ \\
\hline
\end{tabular}

${ }^{\text {a }}$ Percent of leaf pieces that yielded this fungal species from 40 to 45 pieces per leaf sample.
$(14,18,34)$, but the sexual state of the fungus was not observed. Our results are in partial agreement with the results of other researchers $(14,18)$ in that the fungus could be isolated from barley leaves during a cropping season.

The presence of barley foliar pathogens and other aggressive saprophytic fungi could decrease, or prevent entirely, formation of the sexual state, which is a crucial step in overwintering of $P$. tritici-repentis. Even if $P$. tritici-repentis infects barley during the growing season, barley pathogens may not allow the fungus to produce its sexual state by competing for and occupying the niche necessary for its survival. Duczek et al. (9) could not recover the sexual or asexual states of $P$. triticirepentis from barley crop residue. In a study of the effect of a previous crop on tan spot development, disease was sevenfold less on the first leaf through early flag leaf where barley or a nonhost crop was planted (27). The difference in disease severity may be a lack of residue-borne inoculum in those plots where barley was planted the previous year; whereas tan spot was triggered by the inoculum produced on wheat residue. Thus, barley may not have a significant role in the overwintering of the pathogen.

We suspect the fungus is a saprophyte on senescing barley leaves predominantly for three reasons. First, conidia are airborne and can be dispersed long distances $(12,31)$. Conidia are dispersed throughout the growing season and are abundant in the northern Great Plains beginning in July and August (12,20). Secondly, the fungus is a facultative saprophyte and can survive on senescent leaves or leaf area damaged by other pathogens. Thirdly, all 10 isolates recovered from barley were race 1 , because they induced necrosis and chlorosis on the appropriate wheat differentials and did not induce either symptom on M-3 and Salamouni. Prevalence of race 1 on barley

Table 5. Reaction of 12 barley genotypes to five races of Pyrenophora tritici-repentis, Ptr ToxA and ToxB, and a P. teres check

\begin{tabular}{|c|c|c|c|c|c|c|c|c|}
\hline \multirow[b]{2}{*}{ Genotype } & \multicolumn{5}{|c|}{ Races $^{\mathbf{a}}$} & \multicolumn{2}{|c|}{ Ptr Toxins ${ }^{b}$} & \multirow[b]{2}{*}{ P. teres $^{\mathrm{c}}$} \\
\hline & 1 & 2 & 3 & 4 & 5 & ToxA & ToxB & \\
\hline Azure & R1-2 & R1-2 & R1 & $\mathrm{R} 1$ & R1 & I & I & S4-5 \\
\hline Breeder & R1-2 & R1-2 & R1 & R1-2 & R1 & I & I & S4 \\
\hline Bowman & R1-2 & R1-2 & R1 & R1-2 & R1 & I & I & S4-5 \\
\hline Excel & R1-2 & $\mathrm{R} 1$ & $\mathrm{R} 1$ & $\mathrm{R} 1$ & R1-2 & I & I & S4 \\
\hline Firlbeck & $\mathrm{R} 1$ & R1 & R1 & $\mathrm{R} 1$ & R1-3 & I & I & S4-5 \\
\hline Kindred & R1 & R1 & R1 & R1 & R2-3 & I & I & S4 \\
\hline Manduria & R1-2 & $\mathrm{R} 2$ & $\mathrm{R} 1$ & $\mathrm{R} 1$ & $\mathrm{R} 1$ & I & I & S4-5 \\
\hline Monte Cristo & R2-3 & R1-3 & R1-2 & R1-3 & R1-3 & I & I & S4-5 \\
\hline Primus & R1-3 & R2-3 & $\mathrm{R} 1$ & R1-2 & R2-3 & I & I & S4-5 \\
\hline Robust & R1-2 & R1-2 & $\mathrm{R} 1$ & $\mathrm{R} 1$ & R1 & I & I & S4-5 \\
\hline Stander & R1-2 & $\mathrm{R} 1$ & $\mathrm{R} 1$ & R1 & R1-2 & I & I & S4-5 \\
\hline Wolf & R1-2 & R1-2 & $\mathrm{R} 1$ & $\mathrm{R} 1$ & $\mathrm{R} 1$ & I & I & S4-5 \\
\hline ND495 & S5 & & & & & $\mathrm{S}$ & I & R1-2 \\
\hline $6 \mathrm{~B} 365$ & S5 & & & & & I & I & $\mathrm{R} 1-2$ \\
\hline
\end{tabular}

${ }^{a}$ Fungal reaction: $\mathrm{R}=$ resistant $\mathrm{S}=$ susceptible; lesion types indicated by a 1 (resistant) to 5 (susceptible) scale (22). Wheat checks ND495 and $6 \mathrm{~B} 365$ were not challenged by all races.

b Toxin reaction: S = sensitive I = insensitive Purified Ptr ToxA was provided by Dr. Steven Meinhardt, Department of Biochemistry, NDSU. Culture filtrate of ToxB was obtained from isolate DW 7 as described by Orolaza et al. (29).

${ }^{c}$ Isolate 89-19 obtained from Dr. Brian Steffenson, Department of Plant Pathology, NDSU. 
is logical because this is the most prevalent race on wheat in North America $(1,2,3,23)$. This result supports the hypothesis that this fungus exists saprophytically on barley because there was no evidence of selection pressure. If the fungus exists as a saprophyte, it follows that it does not have any selection pressure to bring changes in its virulence, but may still successfully overwinter in some environments.

Reaction of barley genotypes to $P$. tritici-repentis races in the greenhouse. All barley lines except Kindred, Monte Cristo, and Primus developed lesion type 1-2 (resistant) to all isolates of the five races of the fungus. Although Kindred, Monte Cristo, and Primus developed lesion type 3 to some isolates, the number of these lesions was very few (Table 5, Fig. 1, 2). These few lesions did not change the overall rating from resistant to susceptible because, in all cases, the lower values were observed most frequently (Table 5 ). Thus, we did not find any major difference in barley lines based on their temporal (developed between the 1940s or earlier and the 1990s), geographic adaptation (bred in India or in the U.S.), type (two-row or sixrow), and growth habit (spring or winter) characteristics (Table 2).

Isolates of races 1,2 , and 4 , which were collected from different host plant species and geographic locations, were pathogenic but not very virulent on barley. In previous studies $(13,14,34)$, one or two barley lines were tested against very few isolates of the fungus. In addition, these isolates might have belonged to the same race, because the race system was just recently developed or not well recognized when most of these studies were undertaken $(14,21,25,34)$. In one study, barley was found to be intermediate in reaction to the fungus (19); whereas it was highly resistant in the other five studies. These contradictory results might be the result of different barley lines, experimental protocols, rating scales, and/or the fungal isolates used in the experiments. Our results indicate that barley is highly resistant to the fungus and confirm several previous studies. Moreover, they provide a broad picture of barley reaction to $P$. tritici-repentis because they are based on the interaction between 12 barley lines with a broad genetic background and 14 fungal isolates from five races, collected from a wide geographic range and different host plant species.

In reference to completion of Koch's postulates for $P$. tritici-repentis from the greenhouse-inoculated barley seedlings, we were not able to recover the fungus from the infection sites. Our results are contradictory to those of Francl (13), Summerell and Burgess (34), and Krupinsky (19), who recovered the fungus successfully from naturally infected leaves and greenhouseinoculated seedlings. This discrepancy is most likely due to differences in environ-

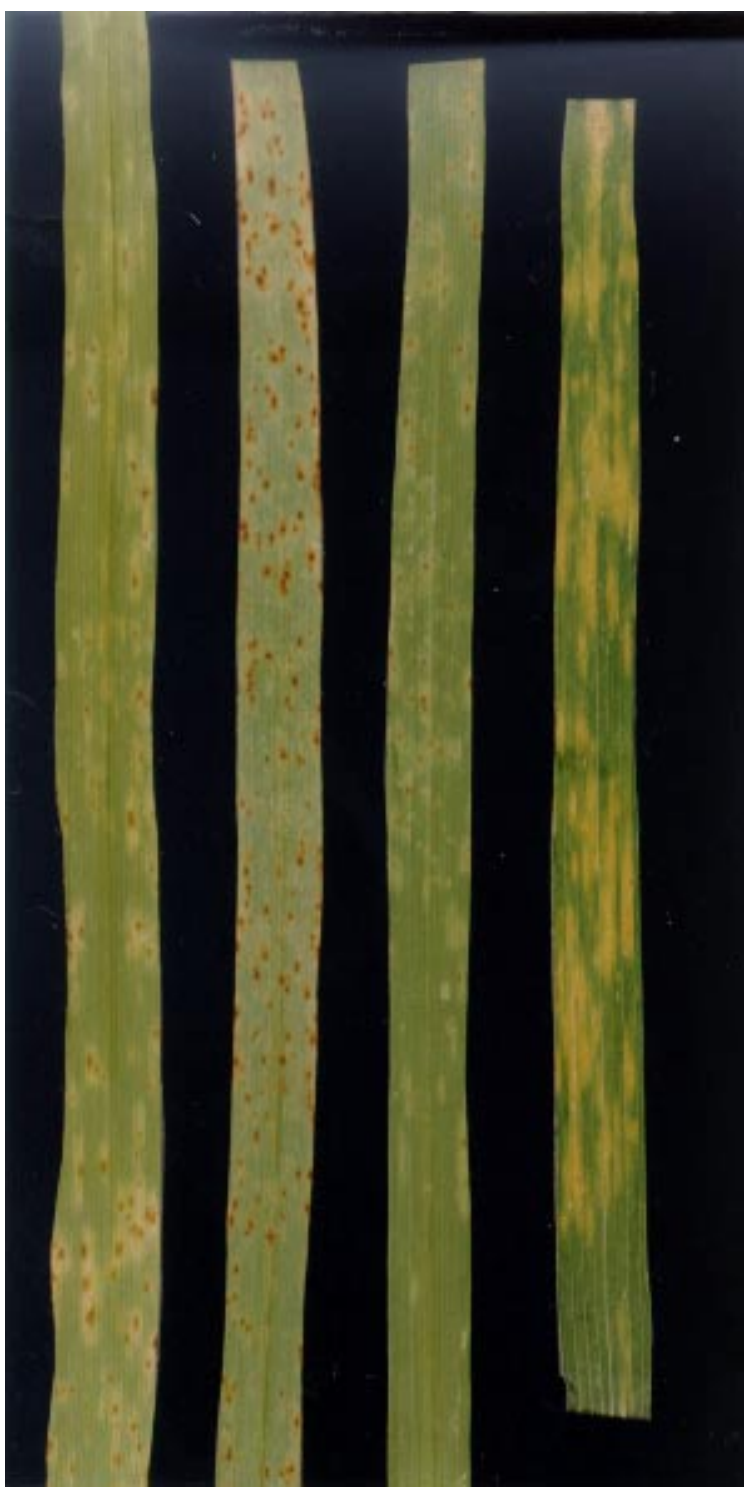

Fig. 1. Reaction of (left to right) Primus barley, Monte Cristo barley, Firlbeck barley, and Katepwa wheat to race 5 isolate DW7 of Pyrenophora tritici-repentis.

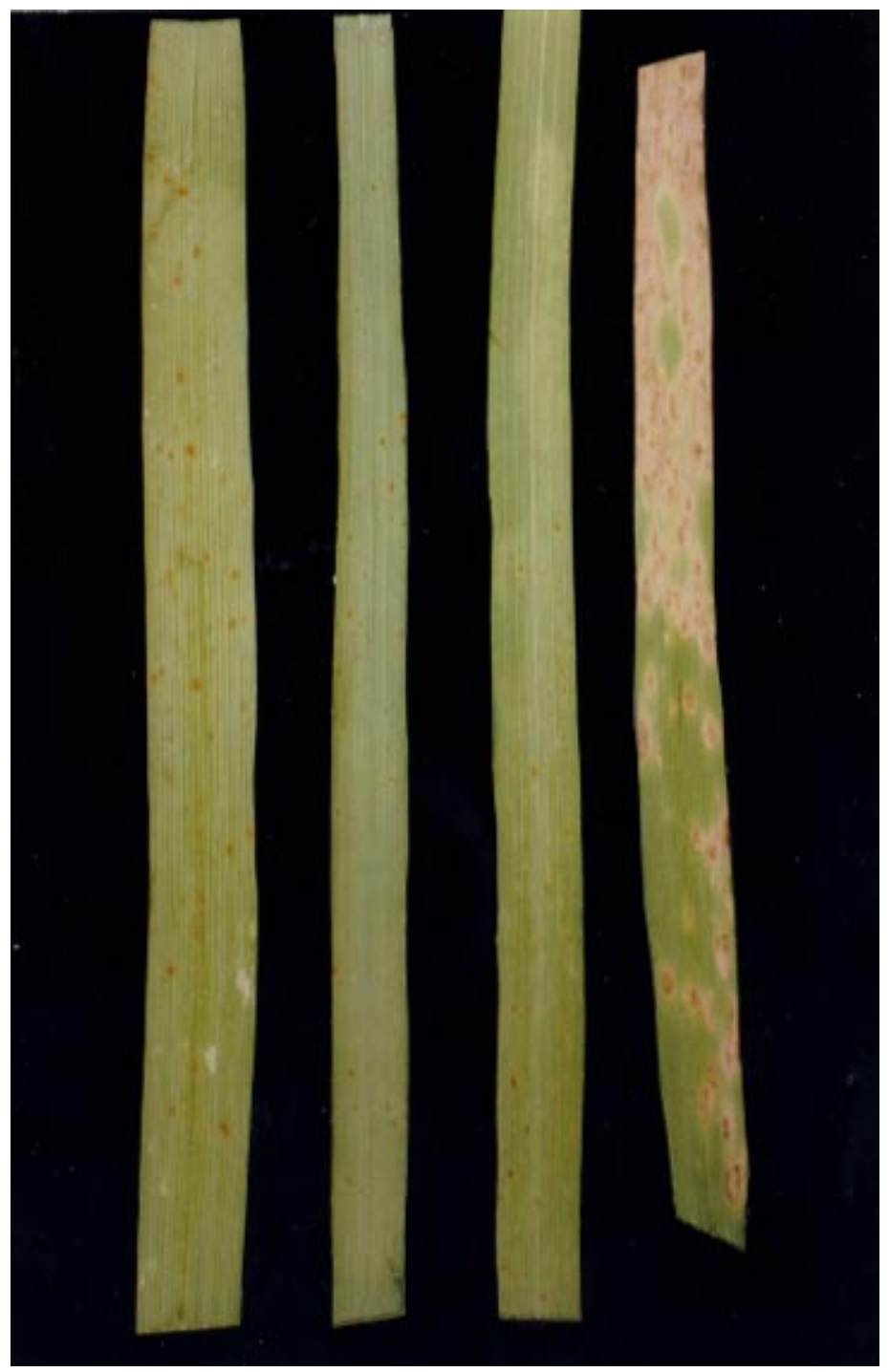

Fig. 2. Reaction of (left to right) Primus barley, Monte Cristo barley, Firlbeck barley, and Glenlea wheat to race 1 isolate Pti2 of Pyrenophora triticirepentis. 
mental conditions or experimental protocols. Failure in recovery of the fungus from the infection sites suggests that resistance genes in metabolically active barley leaves combat $P$. tritici-repentis invasion.

Barley reaction to $P$. tritici-repentis $\mathrm{Ptr}$ ToxA and ToxB. All barley lines were insensitive to the toxins; whereas, ND 495 and Katepwa developed necrosis and chlorosis to Ptr ToxA and Ptr ToxB, respectively. Insensitivity of all barley lines to Ptr ToxA and Ptr ToxB strengthened our conclusion from the inoculation trials, because none of the lines showed susceptibility to $P$. tritici-repentis races. Our results agree with other studies in which barley was insensitive to Ptr ToxA and Ptr ToxB $(4,29,35)$. However, barley developed chlorosis to a partially purified toxin in one study (5), but reaction of the barley line to the fungal inoculation was not described, and the toxin may not have been host-selective. In our study, we screened 12 barley lines from diverse genetic backgrounds and did not find any difference in their reaction to the toxins. Corresponding reactions of the barley genotypes to the fungal isolates and host-specific toxins suggest that they have parallel roles in pathogenicity as suggested in earlier studies $(4,29)$.

Our greenhouse studies and the fungal recovery with a low frequency from a few field samples suggest the role of barley in wheat tan spot epidemiology is insignificant. Barley was very resistant to $P$. triticirepentis and may be a useful source of resistance to tan spot, as molecular techniques are available to transfer genes of interest from unrelated plant species. In addition, prevalence of race 1 on barley, presumably as a facultative saprophyte, tends to exclude the chances of new race development. More survey work is needed to explore the possibility of the sexual state occurring on barley under field conditions in North Dakota and elsewhere.

\section{LITERATURE CITED}

1. Ali, S., and Buchneau, G. W. 1992. Incidence of toxin-producing pathotypes of Pyrenophora tritici-repentis in South Dakota. (Abstr.). Phytopathology 82:1159.

2. Ali, S, and Francl, L. J. 1999. Races of Pyrenophora tritici-repentis on durum in the northern Great Plains of the U.S. (Abstr.) Phytopathology 89:S2.

3. Ali, S., and Francl, L. J. 1998. Race structure of Pyrenophora tritici-repentis isolated from wheat and grasses in the U.S. Great Plains. (Abstr.) Phytopathology 88:S114.

4. Ballance, G. M., Lamari, L., and Bernier, C.
C. 1989. Purification and characterization of a host selective toxin from Pyrenophora triticirepentis. Phys. Mol. Plant Pathol. 35:203-213.

5. Brown, D. A., and Hunger, R. M. 1993. Production of a chlorosis-inducing, host-specific, low-molecular-weight toxin by isolates of Pyrenophora tritici-repentis, cause of tan spot of wheat. J. Phytopathol. 137:221-232.

6. Ciuffetti, L. M., and Tuori, R. P. 1999. Advances in the characterization of the Pyrenophora tritici-repentis-wheat interaction. Phytopathology 89:444-449.

7. Ciuffetti, L. M., Francl, L. J., Ballance, G. M., Bockus, W.W., Lamari, L., Meinhardt, S. W., and Rasmussen, J. B. 1998. Standardization of toxin nomenclature in the Pyrenophora tritici-repentis/wheat interaction. Can. J. Plant Pathol. 20:422-425.

8. De Wolf, E. D., Effertz, R. J., Ali, S., and Francl, L. J. 1998. Vistas of tan spot research. Can. J. Plant Pathol. 20:349-370.

9. Duczek, L. J., Sutherland, K. A., Reed, S. L., Baily, K. L., and Lafond, G. P. 1999. Survival of leaf spot pathogens on crop residues of wheat and barley in Saskatchewan. Can. J. Plant Pathol. 21:165-173.

10. Effertz, R. J., Meinhardt, S. W., Anderson, J. A., Jordahl, J. G., and Francl, L. J. 1998. Identification of a chlorosis-inducing toxin from Pyrenophora tritici-repentis and chromosomal location of a gene conditioning insensitivity in wheat. (Abstr.) Phytopathology 88:S25.

11. Faris, J. D., Anderson, J. A., Francl, L. J., and Jordahl, J. G. 1996. Chromosomal location of a gene conditioning insensitivity in wheat to a necrosis-inducing culture filtrate from Pyrenophora tritici-repentis. Phytopathology 86:459-463.

12. Francl, L. J. 1997. Local and mesoscale dispersal of Pyrenophora tritici-repentis conidia. Can. J. Plant Pathol. 19:247-255.

13. Francl, L. J. 1998. Genesis and liberation of conidia of Pyrenophora tritici-repentis. Can. J. Plant Pathol. 20:387-393.

14. Hosford, R. M. Jr. 1971. A form of Pyrenophora trichostoma pathogenic to wheat and other grasses. Phytopathology 61:28-32.

15. Hosford, R. M. Jr. 1982. Tan spot. Pages 1-24 in: Tan Spot of Wheat and Related Disease Workshop. R. M. Hosford Jr., ed., North Dakota Agric. Exp. Station, Fargo.

16. Jordahl, J. G., and Francl, L. J. 1992. Increase and storage of cultures of Pyrenophora triticirepentis. Page 109 in: Advances in Tan Spot Research. L. J. Francl, J. M. Krupinsky, and M. P. McMullen, eds. North Dakota Agric. Exp. Station, Fargo.

17. Kwon, C. W., Rasmussen, J. B., and Meinhardt, S. W. 1998. Activity of Ptr ToxA from Pyrenophora tritici-repentis requires host metabolism. Physiol. Mol. Plant Pathol. 52:201-212.

18. Krupinsky, J. M. 1982. Observation of the host range of isolates of Pyrenophora trichostoma. Can. J. Plant Pathol. 4:42-46.

19. Krupinsky, J. M. 1992. Aggressiveness of isolates of Pyrenophora tritici-repentis obtained from wheat in the northern Great Plains. Plant Dis. 76:87-91.
20. Krupinsky, J. M. 1992. Collection of conidia and ascospores of Pyrenophora triticirepentis. Pages 91-95 in: Advances in Tan Spot Research. L. J. Francl, J. M. Krupinsky, and M. P. McMullen, eds. North Dakota Agric. Exp. Station, Fargo.

21. Krupinsky, J. M. 1992. Grass hosts of Pyrenophora tritici-repentis. Plant Dis. 76:92-95

22. Lamari, L., and Bernier, C. C. 1989. Evaluation of wheat for reaction to tan spot (Pyrenophora tritici-repentis) based on lesion type. Can. J. Plant Pathol. 11:49-56.

23. Lamari, L., and Bernier, C. C. 1989. Virulence of isolates of Pyrenophora tritici-repentis on 11 wheat cultivars and cytology of the differential host reactions. Can. J. Plant Pathol. 11:284-290.

24. Lamari, L., Sayud, R., Boulif, M., and Bernier, C. C. 1995. Identification of a new race in Pyrenophora tritici-repentis: implications for the current pathotype classification system. Can. J. Plant Pathol. 17:312-318.

25. Maraite, H., Berny, J. F., and Goffin, A. 1992. Epidemiology of tan spot in Belgium. Pages 73-79 in: Advances in Tan Spot Research. L. J. Francl, J. M. Krupinsky, and M. P. McMullen, eds. North Dakota Agricultural Experiment Station, Fargo.

26. McFadden, W., and Harding, H. 1989. Cereal stubble as a source of primary inoculum of leaf spotting pathogens of winter wheat. (Abstr.) Can. J. Plant Pathol. 11:195.

27. McMullen, M. P. 1998. Effect of previous crop on tan spot and Fusarium head blight in wheat. (Abstr.) Phytopathology 88:S116.

28. Misra, A. P., and Singh, R. A. 1972. Pathogenic differences among three isolates of Helminthosporium tritici-repentis and the performance of wheat varieties against them. Indian Phytopathol. 25:350-353.

29. Orolaza, N. P., Lamari, L., and Ballance, G. M. 1995. Evidence of a host-specific chlorosis toxin from Pyrenophora tritici-repentis, the causal agent of tan spot of wheat. Phytopathology 85:1282-1287.

30. Rees, R. G., and Platz, G. J. 1983. Effects of yellow spot on wheat: comparison of epidemics at different stages of crop development. Aust. J. Agric. Res. 34:39-46.

31. Schilder, A. M. C., and Bergstrom, G. C. 1992. The dispersal of conidia and ascospores of Pyrenophora tritici-repentis. Pages 96-99 in: Advances in Tan Spot Research. L. J. Francl, J. M. Krupinsky, and M. P. McMullen, eds. North Dakota Agric. Exp. Station, Fargo.

32. Schilder, A. M. C., and Bergstrom, G. C. 1995. Seed transmission of Pyrenophora tritici-repentis, causal fungus of tan spot of wheat. Eur. J. Plant Pathol. 101:81-91.

33. Shoemaker, R. A. 1962. Drechslera Ito. Can. J. Bot. 40:809-836.

34. Summerell, B. A., and Burgess, L. W. 1988. Saprophytic colonization of wheat and barley by Pyrenophora tritici-repentis in the field. Trans. Br. Mycol. Soc. 90:551-556.

35. Tomás, A., and Bockus, W. W. 1987. Cultivar specific toxicity of culture filtrate of Pyrenophora tritici-repentis. Phytopathology 77: 1337-1366. 